\title{
EL LABORATORIO DE POLICÍA CIENTÍFICA DE LA UJI: PRIMER AÑO DE PRÁCTICA FORENSE
}

\section{Cristina Guisasola Lerma ${ }^{a}$, Sergio Bosquet Pastor $^{\mathrm{b}}$ y Felix Tomás Bermejo Díaz}

${ }^{a}$ Vicedecana Grado en Criminología y Seguridad Universidad Jaume I, Castellón, cguisa@uji.es ${ }^{\mathrm{b}}$ Guardia Civil, Especialista en Policía Judicial y Criminalística, Comandancia de la Guardia Civil de Castellón, sergiobosquet.sbp@,gmail.com y ${ }^{c}$ Brigada Guardia Civil, profesor asociado derecho penal Universidad Jaime I, Castellón, fbermejo@uji.es

\begin{abstract}
The Teaching Innovation Project "Legal Clinic: Research and forensic practice" has lead the creation of a Forensic Science Laboratory in UJI in which students can perform personal identification practices, lofoscópica identification documentoscopy, police photography and video, or identification of footprints, among others, space provided for those inventariables and consumables that are necessary to carry out such practices.
\end{abstract}

Keywords: Criminology, Scientifics Police, Research and Forensic Practice.

\footnotetext{
Resumen

El Proyecto de Innovación Docente "Clínica legal: Investigación y práctica forense" se ha dirigido a la creación de un Laboratorio de Policía Científica en la UJI en el que los alumnos pueden realizar prácticas de identificación personal, identificación lofoscópica, documentoscopia, fotografía y vídeo policial, o identificación de huellas de pisadas, entre otras, espacio dotado de materiales inventariables y fungibles necesarios para llevar a cabo dichas prácticas.
}

Palabras clave: Criminología, Policía Científica, Investigación y Práctica Forense. 


\section{Introducción: El Grado en Criminología y Seguridad de la UJI y la asignatura Policía Científica}

Tal y como se expuso en nuestra intervención en el I Congreso de Criminología de la Comunidad Valenciana, en titulaciones de nueva implantación como lo es el Grado en Criminología y Seguridad, la presencia de asignaturas eminentemente técnicas, como lo es la asignatura "Policía Científica" requería que la Universidad se dotara de medios e instrumentos que permitieran a los alumnos, no sólo la adquisición de competencias y destrezas de carácter teórico, sino también de aquellas que se precisen para poder desempeñar de manera solvente las funciones propias de su profesión. La asignatura de Policía Científica, cuyo objeto es el estudio de los principales métodos de investigación criminal y, más concretamente, el descubrimiento y verificación científica del delito y del delincuente, se imparte en el tercer curso del Grado en Criminología y Seguridad con carácter de obligatoria y anual. Tanto la citada asignatura como la de Métodos y Técnicas de Intervención Policial revisten un marcado carácter específico y técnico, que requieren, a la hora de llevar a cabo la formación práctica de los alumnos, un lugar físico, distinto del aula donde se imparte la docencia teórica, dotado, del material inventariable y fungible necesario para poder desarrollar las prácticas propias de las asignaturas.

Pendientes las firmas de Convenios singulares para realizar las prácticas externas, ambas instituciones se prestaron a colaborar con nosotros organizando visitas prácticas tanto al Laboratorio de la Comandancia de la Guardia Civil de Castellón, como a la Comisaría de la Policía Nacional de Castellón. En este último caso se modularon dos ciclos mensuales (uno en cada quincena): en el primero, tras el paso por el aula de formación donde se les explicó la estructura del CNP y de la Comisaría provincial, las funciones y especialidades dentro de la Policía Judicial y de la Policía Científica, se visitaron las dependencias de la Brigada de Policía Científica.

En el caso de la Guardia Civil debido al elevado número de asistentes y por tratarse el Laboratorio de Criminalística de una zona sensible y de acceso restringido, la visita fue realizada en dos ciclos mensuales, ciclos que se subdividieron. Cada grupo y de forma alterna, se les mostró un video de la Organización y Estructura de la Guardia Civil, funciones y especialidades que cuenta el Instituto, y durante la visita al laboratorio de criminalística se les informo de las funciones y cometidos de sus especialistas, mostrándoles Técnicas de Iluminación mediante Luces Forense, y funcionamiento del Sistema Automatizado de Identificación Dactilar (SAID). Hay que destacar que el Convenio Marco con la Guardia Civil fue suscrito el pasado día 12 de septiembre de 2014 por el Secretario de Estado de Seguridad (Ministerio del Interior) y el Rector Magnífico de la universidad. Actualmente se encuentra en fase de tramitación un convenio singular de prácticas entre la UJI y la Comandancia de la Guardia Civil de Castellón que posibilite a los alumnos de último año realizar las prácticas académicas externas en dependencias oficiales de la Guardia Civil, con el objeto de conseguir un equilibrio entre la formación teórica y práctica del estudiantado, la adquisición de metodologías para el desarrollo profesional y facilitar la empleabilidad futura de este colectivo.

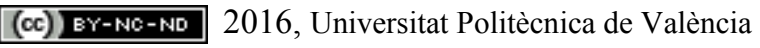


Pese a estas visitas puntuales, se hacía evidente la necesidad de un espacio donde los estudiantes pudieran llevar a cabo de una manera correcta las prácticas y horas de laboratorio contempladas en el Plan de estudios de la asignatura. Por dicha razón solicitamos un Proyecto de Innovación Docente que bajo el título "Clínica legal: Investigación y práctica forense" pretendía la puesta en marcha de un Laboratorio de Policía Científica, en el que los alumnos pudieran realizar prácticas de identificación personal, identificación lofoscópica, documentoscopia, fotografía y vídeo policial, o identificación de huellas de pisadas, entre otras, espacio que sería dotado de aquellos materiales inventariables (aquellos con los que ya cuente la UJI) y fungibles que resulten necesarios para llevar a cabo dichas prácticas, y de los que no disponga ya la universidad.

A día de hoy es ya una realidad, disponiendo de una aula adaptada donde se ejercen funciones técnicas y específicas de Policía Científica. Tras su inauguración oficial en presencia del rector, Subdelegado del Gobierno y demás autoridades, el "Laboratorio de Criminalística" comenzó su andadura en el curso académcio 2014/15. Iniciado el Curso y antes de comenzar las prácticas en el laboratorio se fueron detectando las necesidades de material mínimo; de un lado productos como los reactivos químicos, asi como otros reactivos de reposición anual, al igual que otros materiales como los guantes, levantadores de huellas, el Mikrosil, el Durocast, etc.

El presente curso académico solicitamos de nuevo la continuación del proyecto de mejora educativa "Clínica legal: Investigación y práctica forense (II)" y, a través de la Ofícina Técnica d'Obres i Projectes, perteneciente al Vicerrectorado de Campus, Infraestructuras y Nuevas Tecnologías, se procedió a la adquisición del siguiente material:

- Equipos informáticos PCs. con software de

- Edición de video

- Edición de fotografía.

- Confección y tratamiento de planos/croquis.

- Captura de fotografía visualizada a través del ordenador (la captura se realizaría mediante el uso de la cámara fotográfica).

- Cámaras fotográficas y estativos.

- Cámara de Vaporización de Huellas Latentes mediante CYANOCRILATO y Extractor de Vapores Cianocrilato.

\section{Objetivos}

El objetivo principal del proyecto consiste en desarrollar competencias relativas al ejercicio práctico de los conocimientos adquiridos en asignaturas "Policía Científica" y "Métodos y Técnicas de Investigación Policial”, del Grado en Criminología y Seguridad. Se pretende que los alumnos del Grado en Criminología y Seguridad adquieran las competencias necesarias para poder llevar a cabo las labores investigadoras propias de los criminólogos, tales como el manejo del equipamiento técnico requerido para poder realizar informes y reconocimientos dactiloscópicos, informes de documentoscopia o reseña personal entre 
otros, así como la fotografía y vídeo policial, o la identificación de huellas de pisadas, entre otras. En esencia, ser conocedores de la actividad policial encargada de la investigación técnica del delito.

\section{Desarrollo de la innovación: Puesta en marcha de las prácticas en el Laboratorio de Policía Científica}

La asignatura de Policía Científica supone un reto para el docente que la imparte ya que la mayor parte del programa es de carácter especifico y técnico, con el fin de cubrir el objetivo impuesto en la planificación de actividades relacionadas con las practicas programadas en la Guía Docente, se cuenta con la colaboración directa de un experto en Criminalística de la Unidad Orgánica de Policía Judicial de la Guardia Civil de Castellón, (Sergio Bosquet).

Para captar la atención y el interés del alumnado para que fuera participe en las prácticas, estas se realizan de menor a mayor intensidad, sin ser las primeras de menor importancia que las siguientes y siendo todas de suma importancia en el proceso penal. Las prácticas que se llevan a cabo en el laboratorio para la formación de sus alumnos consisten:

\subsection{Confección y familiarización con los diversos tipos de documentos y formularios de uso policial}

Realizan prácticas cumplimentando documentos que guardan relación con la actividad técnica y científica, como son la hoja de toma de indicios/evidencias y cadena de custodia, el documento de seguimiento e identificación dactilar del detenido, formularios para la obtención del ADN a partir de muestras biológicas provenientes del detenido/investigado o sospechosos en el marco de una investigación criminal, o en los procedimientos de identificación de cadáveres o de averiguación de personas desaparecidas.

\subsection{Recogida de Indicios biológicos y lofoscopicos y uso de contenedores para su traslado \\ 3.2.1. "Recogida de muestras biológicas"}

En criminalística y policía científica, entre los indicios que se recogen y que permiten obtener un mayor en número resultados positivos en la investigación técnico científica, son los indicios de carácter biológico, pero dada su facilidad con la que se pueden contaminar, requiere de métodos y técnica para su recogida, para ello los alumnos han utilizado métodos de fricción aplicados en aquellos indicios/evidencias de procedencia dubitada, como es el uso de hisopos impregnados de agua estéril, uso de jeringuillas para recogida de residuos líquidos, toma de muestras de saliva por medio de FTA, y uso de procedimientos sobre la retirada de sangre seca en superficies porosas y no porosas, haciendo uso de diversos contenedores para su almacenamiento y remisión, como son bolsas de papel o sobres y cajas de cartón de diferentes tamaños, tubos de ensayo, etc.

(cc) EY-NC-ND 2016, Universitat Politècnica de València 


\subsection{2. "Búsqueda de huellas lofoscopicas latentes"}

Otro de los trabajos en el que los alumnos se muestras muy interesados y participan de manera muy activa es durante la práctica de "Búsqueda de Huellas Latentes Lofoscópicas (dactilares y palmares) en diferentes tipos de superficies", porosas y no porosas, utilizándose las diferentes clases de reveladores "Pulverulentos o Líquidos" concretándose en el uso y manejo de los reveladores "mecánicos y magnéticos", "físicos y químicos", combinando la practica con equipos de alta tecnología como es la Cámara de Vaporización de Cianocrilato. Uno de los reveladores químicos que debido a su peculiar método de trabajo y resultado, llama la atención de los alumnos es la Violeta Genciana, reactivo con la que realizan prácticas en materiales cuyas superficies son adhesivas y cuyos indicios se recogen en aquellos delitos de mayor gravedad (Robo con Violencia e Intimidación, Terrorismo, etc.) para silenciarlas o inmovilizar a las víctimas. Finalizada la pericia se constata por los propios alumnos, que la creencia que cualquier superficie alberga una posible huella latente, es falso.

También se ejercitan y son conocedores de los distintos métodos que se utilizan para el levantamiento y traslado de las huellas latentes, primeramente mediante el uso de la fotografía y seguidamente con el uso de gelatinas (trasplantadoras), cajas de cartón para la remisión de evidencias portadoras de lofogramas latentes.

\subsection{Análisis de huellas dactilares y palmares}

Se practica el sistema español de identificación dactilar implantado en España por Federico Oloriz Aguilera, para el estudio y análisis de huellas dactilares, conociendo e identificando los tipos de dactilograma, sistemas nucleares, núcleos, deltas, o formulación, etc.), igualmente realizan análisis de lofogramas palmares, diferenciando sus regiones, los pliegues y elementos (pinos, bucles o deltas).

\subsection{Fotografía Policial}

No siendo de menor interés que las anteriores y considerada tras su ratificación en juicio oral como prueba pre constituida, se les ha dado a conocer los métodos y técnicas de la fotografía policial, (Fotografía de conjunto general, panorámico, conjunto parcial, detalle y macrofotografía). Así, se efectuan fotografías de campo en espacios abiertos y cerrados y fotografías en el interior del laboratorio de criminalística mediante uso de cámaras fotográficas y la utilización de estativos para la fotografía de detalle y macrofotografía.

\subsection{La Inspección Técnico Ocular (ITO)}

Adquiridos los conocimientos sobre los métodos y técnicas sobre fotografía policial, recogida de indicios/evidencias y búsqueda y traslado de huellas latentes, etc., llega el momento de trasladar las prácticas al reciento exterior del laboratorio, cuyo objetivo es ejecutar la denominada "Criminalística de Campo", es decir, conocer directamente el

(c)) EY-NC-ND 2016, Universitat Politècnica de València

Congreso In-Red (2016) 
"Escenario Criminal", para ello los alumnos proceden a la escenificación de diferentes escenarios, donde intervienen haciéndose valer como la persona fallecida, es decir, el cadáver. También se incorporan otros indicios como armas o herramientas, rastros de sangre, o huellas latentes, etc., practicando la "Inspección Técnico Ocular" (ITO). Este ejercicio en la Policía Científica y en Criminalística está considerado en la investigación criminal como el de mayor trascendencia e importancia ya que de su buen hacer puede depender el resultado del proceso penal.

\subsection{La Reseña Policial Lofoscopica personas detenidas}

Los alumnos en la práctica asumen los personajes de policías y delincuentes, tras mostrarles el método para la realización de la "Tarjeta Lofoscópica", tarjeta que contiene, las diez impresiones dactilares de los dedos de las manos, las impresiones palmares completas de la mano derecha e izquierda, y por último los bordes hipotenares, también conocidos como "puño del escritor", formando grupos de dos cada uno de ellos ejecutan los diferentes roles de policías y delincuentes confeccionándose su propia Tarjeta Lofoscópica.

\subsection{Confección de la Reseña policial fotográfica}

Esta práctica consiste en mostrar a los alumnos como fotografiar los distintos perfiles del rostro y rasgos del delincuente, ya que su resultado es un elemento identificador de suma importancia en la investigación de carácter criminal y en asunto humanitario.

Al igual que en la reseña dactilar los alumnos forman grupos de dos y con los roles de policías y delincuentes y mediante las cámaras fotográficas del Laboratorio de Criminalística se van fotografiando respectivamente los perfiles del rostro, de cuerpo entero y rasgos como la huella dactilar una vez impresa, cicatrices o tatuajes que portan, finalmente para incluirlos en un Informe Fotográfico.

\subsection{Moldeado de herramientas y huellas de calzado}

Este ejercicio de recogida de "Trazas de herramientas" y "Vaciado de huellas de calzado o neumáticos en un escenario criminal", cada uno de los alumnos procede a moldear las trazas creadas previamente con herramientas (tenazas, palancas o huellas dactilares, con moldeadores (Durocast y Mikrosil), pasta similar a la masilla.

Los alumnos, para ejecutar esta práctica del moldeado de la huella de calzado, previamente descansan su huella de calzado en una superficie apta, para proceder a continuación ellos mismo a realizar un vacio de la huella, mediante uso de escayola.

\subsection{Método de recogida de residuos de disparo y cumplimentación de la hoja de análisis}

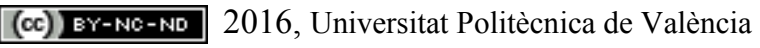


Los alumnos en esta clase tienen ocasión de conocer el método para poder determinar si una persona ha hecho uso de armas de fuego. Práctica que se ejecuta con un portaminas, un porta muestras adhesivo y finalmente cumplimentando de formulario de la recogida de residuos de disparo.

\subsection{Documentoscopia. Medidas de Seguridad documento privado/oficial y billetes Euro}

En esta práctica los alumnos toman contacto con documentos de origen indubitado y dubitado, descubriendo las medidas de seguridad de aquellos de carácter oficial o privados y como dice la Fabrica Nacional de Moneda y Timbre, con unas simples maniobras de: Toque, Mire y Gire, descubren algunas de las medidas de seguridad que se hallan incorporadas en los billetes de Euro, determinando su autenticidad o falsedad. Igualmente no siendo visibles al ojo humano otras de las medidas que presentan los billetes y documentos, se comprueban mediante el uso de Lámparas de Wood o Luz negra.

\subsection{Armas y cartuchos}

Tras la teoría impartida sobre armas y cartuchos, se tiene contacto con armas enumeradas en las distintas categorías del reglamento de Armas, como son armas de fuego, aire comprimido, detonadoras o prohibidas y a su vez tratan la cartuchería metálica, semimetálica y plástica, diferenciando los cartuchos de percusión anular y central.

\section{Resultados}

Los alumnos ya perciben y sienten como la asignatura de Policía Científica les ha traslado a la realidad de la investigación criminal. Resumiendo la experiencia está resultando altamente productiva y rentable en la formación del alumnado en la asignatura de Policía Científica.

Por lo expuesto se considera la necesidad de continuar y seguir apostando por la incorporación de nuevos equipos y en la innovación de los trabajos en el Laboratorio de Criminalística del Grado de Criminología de la Facultad de Ciencias Jurídicas.

\section{Conclusiones}

Concluiremos comentando que es en sede del Laboratorio donde se llevan a cabo la actividad docente conocida como Training Day o Practica UJI: tras una conferencia inaugural del decano de la facultad de Ciencias Jurídicas y Económicas, los estudiantes de bachiller de diferentes institutos de la provincia de Castellón visitan instalaciones de la misma. En el Grado en Criminología y Seguridad los docentes de la asignatura llevan a cabo en varias sesiones actividades prácticas consistentes en el revelado de huellas. 


\section{Referencias}

BOSQUET PASTOR, S. (2015): Criminalística Forense. Valencia: Tirant lo Blanch

BOSQUET PASTOR, S. (2015): La Lofoscopia y sus formas. Valencia : Tirant lo Blanch 